\title{
Reversible pulmonary arterial hypertension associated with interferon-beta treatment for multiple sclerosis
}

\author{
E Gibbons BSc, S Promislow MD, RA Davies MD, G Chandy MD, DJ Stewart MD, \\ V Contreras-Dominguez MD, C Pugliese RN, R Dunne RN, LM Mielniczuk MD
}

\begin{abstract}
E Gibbons, S Promislow, RA Davies, et al. Reversible pulmonary arterial hypertension associated with interferon-beta treatment for multiple sclerosis. Can Respir J 2015;22(5):263-265.

Interferon (IFN) therapy has an important role in the treatment of multiple sclerosis and chronic hepatitis C infection. A few case reports have described an association between IFN therapy and the development of irreversible pulmonary arterial hypertension (PAH), and it is currently listed as a possible drug-induced cause of PAH in the most recent classification of pulmonary hypertension. A causal link between IFN use and PAH remains to be elucidated; many reports of PAH resulting from IFN occur in individuals with some other risk factor for PAH. The authors present a case involving a patient with multiple sclerosis with no known risk factors for $\mathrm{PAH}$, who developed severe PAH after exposure to IFN therapy. The patient experienced significant clinical and hemodynamic improvement, with normalization of her pulmonary pressures after the initiation of combination therapy for PAH. At 28 months after diagnosis, she remains asymptomatic with no hemodynamic evidence of PAH and has been off all PAH therapy for 10 months.
\end{abstract}

Key Words: Diagnosis; Interferon treatment; Multiple sclerosis; Pulmonary artery hypertension

\section{Learning Objectives}

- To discuss the clinical presentation of a patient with a new diagnosis of pulmonary arterial hypertension (PAH).

- To recognize interferon (IFN) therapy as a potential cause of PAH.

CanMeds Competency: Medical Expert

Pretest

- What initial tests are recommended in the diagnostic work-up of a patient with suspected PAH?

- When is dual therapy indicated for the treatment of PAH?

FN use has been associated with the development of PAH in rare 1 cases. In all cases, prolonged use was associated with a severe and irreversible form of the disease. We report a patient who developed severe PAH after undergoing IFN-beta therapy for three years. The present report is the first description of a patient with potential IFNinduced PAH whose symptoms and hemodynamics normalized after the introduction of upfront combination therapy.

\section{CASE PRESENTATION}

A 45-year-old woman with a history of multiple sclerosis (MS) was admitted to the coronary care unit for hypoxia, chest pain and shortness of breath. This patient was diagnosed with MS three years previously and was placed on IFN-beta for the management of her MS symptoms at that time. The patient had a history of syncope in December 2011 and April 2012, with progressive shortness of breath,

\section{L'hypertension artérielle pulmonaire réversible associée au traitement à l'interféron bêta pour traiter la sclérose en plaques}

L'interféron (IFN) joue un rôle important dans le traitement de la sclérose en plaques et de l'infection par le virus de l'hépatite C chronique. Quelques rapports de cas ont décrit une association entre le traitement à l'IFN et l'apparition d'une hypertension artérielle pulmonaire (HAP) irréversible. La plus récente classification de l'hypertension pulmonaire l'inclut dans les causes possibles d'HAP induite par les médicaments. Le lien causal entre l'utilisation de l'IFN et l'HAP n'est pas encore établi. De nombreux cas d'HAP causée par l'IFN sont signalés chez des personnes ayant un autre facteur de risque d'HAP. Les auteurs exposent le cas d'une patiente atteinte de sclérose en plaques ne présentant aucun facteur de risque connu d'HAP qui a développé une grave HAP après avoir été exposée à un traitement à l'IFN. La patiente a présenté une amélioration clinique et hémodynamique importante, et ses tensions pulmonaires se sont normalisées après l'initiation d'une thérapie associative contre l'HAP. Vingt-huit mois après le diagnostic, elle demeure asymptomatique, sans manifestation hémodynamique d'HAP, et ne prend aucun traitement contre l'HAP depuis dix mois.

fatigue and atypical chest pain culminating in an admission to hospital for hypoxemia in September 2012 with New York Heart Association (NYHA) class III symptoms. Her initial examination revealed a blood pressure of $121 / 58 \mathrm{mmHg}$, with a heart rate of 100 beats/min and an oxygen saturation of $90 \%$ on $5 \mathrm{~L}$ of oxygen by nasal prongs. She was found to have a jugular venous pressure of $5 \mathrm{~cm}$ above the sternal angle, with a split second heart sound and a loud P2. Her other medical history was otherwise unremarkable except for mild hypertension, with no vascular, connective tissue or thromboembolic disease. The initial echocardiogram showed a significant pattern of right ventricular dysfunction with moderate dilation and moderate systolic dysfunction of the right ventricle, moderate to severe tricuspid regurgitation, a flattened septum consistent with right ventricular overload and an elevated right ventricular systolic pressure (RVSP) of $64.9 \mathrm{mmHg}$. There was also a patent foramen ovale contributing to her hypoxia. A diagnostic right heart catheterization (RHC) revealed a pulmonary artery pressure of 71/33 $\mathrm{mmHg}$ with a mean of $47 \mathrm{mmHg}$, mean right atrial pressure of $6 \mathrm{mmHg}$, pulmonary wedge pressure of $3 \mathrm{mmHg}$, cardiac output of $3.25 \mathrm{~L} / \mathrm{min}$, cardiac index of $2.45 \mathrm{~L} / \mathrm{min} / \mathrm{m}^{2}$ and pulmonary vascular resistance of 13.5 Wood units with no response to nitric oxide. Coronary angiogram revealed normal coronary arteries. Pulmonary function testing was unremarkable, with a forced vital capacity (FVC) of $2.83 \mathrm{~L}$ (100\% predicted), a forced expiratory volume in $1 \mathrm{~s}\left(\mathrm{FEV}_{1}\right)$ of $2.47 \mathrm{~L}$ (102\% predicted) and an $\mathrm{FEV}_{1} / \mathrm{FVC}$ ratio of $87 \%$. A computed tomography scan was consistent with $\mathrm{PAH}$, with no evidence of pulmonary emboli or evidence of pulmonary vascular occlusive disease. A diagnosis of severe PAH was established. At this time, the IFN was stopped and the patient was treated aggressively with upfront oral combination therapy of ambrisentan $5 \mathrm{mg}$ daily and tadalafil $40 \mathrm{mg}$ daily. Intravenous prostacyclins were not initiated at that time due to

University of Ottawa Heart Institute, Ottawa, Ontario

Correspondence: Dr LM Mielniczuk, University of Ottawa Heart Institute, 40 Ruskin Avenue, Ottawa, Ontario K1Y 4W7.

Telephone 613-761-4039,fax613-761-4877,e-maillmielniczuk@ottawaheart.ca 
TABLE 1

Hemodynamic improvement with oral combination therapy in a patient with possible interferon-induced pulmonary arterial hypertension

\begin{tabular}{|c|c|c|c|c|c|}
\hline Variable & $\begin{array}{l}\text { Diagnosis } \\
\text { (September 2012) }\end{array}$ & January 2013 & March 2013 & March 2014 & June 2014 \\
\hline Medication(s) & None & Tadalafil and ambrisentan & Tadalafil and ambrisentan & Ambrisentan & None \\
\hline \multirow[t]{3}{*}{ Echocardiogrpahy } & $\begin{array}{l}\text { Moderate RV dysfunction } \\
\text { and dilation }\end{array}$ & $\begin{array}{l}\text { Normal RV size and } \\
\text { function }\end{array}$ & $\begin{array}{l}\text { Normal RV size and } \\
\text { function }\end{array}$ & $\begin{array}{l}\text { Normal RV size } \\
\text { and function }\end{array}$ & $\begin{array}{l}\text { Normal RV size } \\
\text { and function }\end{array}$ \\
\hline & Moderate TR & Mild TR & Mild TR & Trace TR & Trace TR \\
\hline & RVSP 65 mmHg & RVSP 26 mmHg & RVSP 28 mmHg & RVSP 26 mmHg & RVSP $27 \mathrm{mmHg}$ \\
\hline Systolic PAP, mmHg & 71 & & 13 & 19 & \\
\hline $\mathrm{PAP}, \mathrm{mmHg}$ & 47 & & 9 & 9 & \\
\hline PCWP, mmHg & 3 & & 4 & 4 & \\
\hline Cardiac output, L/min & 3.25 & & 3.96 & 3.57 & \\
\hline Cardiac index, L/min & 2.45 & & 2.98 & 2.58 & \\
\hline Pulmonary artery oxygen saturation, \% & 64 & & 76 & 70 & \\
\hline New York Heart Association class & III & II & I & I & 1 \\
\hline
\end{tabular}

PAP Pulmonary arterial pressure; PCWP Pulmonary capillary wedge pressure; RV Right ventricle; RVSP RV systolic pressure; TR Tricuspid regugitation

patient preferences. The patient was also started on warfarin and her ambrisentan dosage was increased to the target dosage of $10 \mathrm{mg}$ daily after four weeks. She was weaned off oxygen before discharge from hospital and was able to walk $324 \mathrm{~m}$ on 6 -min walk test when she was seen in clinic after being on therapy for approximately four weeks.

The patient has been followed for a total of approximately 28 months since diagnosis. Since discharge, she showed significant clinical improvement and no signs of right heart failure (Table 1). A repeat echocardiogram was performed three months after initial hospitalization, which revealed a right ventricle normal in size and function and an RVSP of $25.8 \mathrm{mmHg}$. By four months after diagnosis, the patient had improved to NYHA II status, enabling her to gradually return to work. Subsequent to this, she experienced a slight increase in her level of fatigue in the setting of an MS flare, which required pulse steroids followed by maintenance Copaxone (Teva Neuroscience, Israel) therapy. An episode of orthostatic syncope in March 2013 (seven months after diagnosis) prompted a repeat RHC. The test results indicated normal pulmonary hemodynamics with a pulmonary artery pressure of $13 / 3 \mathrm{mmHg}$ and a mean of $9 \mathrm{mmHg}$, mean right atrial pressure of $2 \mathrm{mmHg}$, pulmonary wedge pressure of $4 \mathrm{mmHg}$, cardiac output of $3.96 \mathrm{~L} / \mathrm{min}$, cardiac index of $2.98 \mathrm{~L} / \mathrm{min} / \mathrm{m}^{2}$ and pulmonary vascular resistance of 1.26 Wood units. Her syncope was believed to be secondary to a combination of hypovolemia and orthostasis and her diuretic and angiotensin-converting enzyme inhibitor were held at this time.

The patient was seen again in clinic at the 12-month mark. At this time, she remained asymptomatic with NYHA functional class (FC) I symptoms and was able to walk $432 \mathrm{~m}$ on 6 -min walk test with no dyspnea. A repeat echocardiogram demonstrated normal right ventricular size and function with an estimated RVSP of $26 \mathrm{mmHg}$. Given the ongoing stability and absence of abnormal pulmonary pressures, the patient was cautiously weaned off one PAH agent (tadalafil) and maintained on monotherapy for PAH (ambrisentan).

A repeat routine RHC was performed in March 2014 (18 months after diagnosis), which continued to demonstrate normal pulmonary hemodynamics (pulmonary artery pressure of $19 / 3 \mathrm{mmHg}$ [mean $9 \mathrm{mmHg}]$ ) on monotherapy for six months. Following this, her ambrisentan was weaned and then discontinued. The patient remains NHYA FC I, cycles regularly and has returned to work with no limitation. This raises the question of whether the IFN was responsible for PAH and if the resolution and ongoing stability can be attributed to the dual therapy or the discontinuation of IFN.

\section{DISCUSSION}

There have been few case reports published suggesting a link between PAH and the use of IFN-alpha or IFN-beta; some illustrate irreversible progressive $\mathrm{PAH}$, while others demonstrate modest improvement in functional capacity and symptoms with ongoing PAH treatment (1-5). However, to date, none have described complete resolution of pulmonary hemodynamics to normal values with discontinuation of IFN and aggressive upfront combination therapy for PAH, nor such a robust resolution of symptoms (which has been sustained even with discontinuation of PAH therapy).

A mechanistic link between IFN and the development of PAH has been suggested in previous experimental research. Hanaoka et al (6) demonstrated that the thromboxane cascade, a mediator of inflammation, is directly involved in the effect of IFN on the lungs and may be a mediator of PAH. Links between endothelin-1 and IFNs have also been described (7). It has recently been demonstrated that IFN-alpha and IFN-beta stimulation can activate pulmonary vascular cells to release endothelin-1 (8).

Treatment of PAH with combination therapy of endothelin-receptor antagonist, prostacyclin derivatives or phosphodiesterase type 5 inhibitors is becoming increasingly common in the setting of lack of clinical improvement or deterioration on a monotherapy. Sequential combination therapy is strongly recommended for PAH patients who exhibit an inadequate clinical response to monotherapy (grade 1A recommendation) based on current recommendations (9). The evidence for upfront combination therapy has not been well established (current recommendation grade IIb) but can be considered in certain clinical scenarios (10), and preliminary results from the A Study of First-Line Ambrisentan and Tadalafil Combination Therapy in Subjects With Pulmonary Arterial Hypertension (AMBITION) trial (11), the largest double-blinded randomized control trial investigating this question to date, appear to be promising. In a comparison of upfront combination therapy with ambrisentan and tadalafil to first-line monotherapy with either ambrisentan or tadalfil in FC II or III PAH patients, the AMBITION trial has demonstrated a reduction in the risk of clinical failure by $50 \%$ with combination therapy compared with monotherapy with no significant difference in the rates of serious adverse events and events leading to discontinuation of therapy (11). Once published, this trial may ultimately contribute to a paradigm shift in terms of how patients initially presenting with PAH are managed.

Despite the absence of a prospective case control study establishing a link between IFN and PAH, IFN use is considered to be a possible risk factor for PAH. Previous reports have suggested that the resultant PAH is often irreversible and progressive. The marked clinical improvement and sustained normalization of pulmonary pressures 28 months after diagnosis has not been previously described and has allowed for discontinuation of all PAH therapies. Whether this was due to cessation of IFN therapy or upfront combination therapy cannot be determined. Further study is needed to identify the precise pathophysiology of the problem and determine whether clinical/physiological markers can 
predict or explain a more favourable short-term prognosis or potentially identify targets for different treatment strategies.

\section{Post-test}

- What initial tests are recommended in the diagnostic work-up of a patient with suspected PAH?

This patient presented with progressive shortness of breath, hypoxia and signs of right heart strain. Given her clinical presentation, pulmonary hypertension is high on the differential list. An initial echocardiogram supports the diagnosis but further testing was needed to confirm the etiology. The computed tomography scan and pulmonary function tests were performed to rule out intrinsic lung disease. While a ventilation/perfusion lung scan was not performed in the present case, it is the preferred imaging modality if chronic thromboembolic disease is suspected due to its higher sensitivity relative to computed tomography pulmonary angiogram. An RHC was essential to confirm the diagnosis, evaluate the severity of PAH and rule out any elevation of left-sided filling pressures that would suggest a cardiac cause.

- When is dual therapy indicated for the treatment of PAH?

This is a case of two PAH-specific medications used simultaneously in the upfront treatment of patients with PAH. The current guidelines endorse the use of combination therapy in a sequential fashion in patients not meeting treatment goals with monotherapy. It is not certain whether the patient's clinical improvement was due to cessation of the IFN or upfront combination therapy. However, no previous reports have identified this degree of sustained response after discontinuation of long-term IFN therapy. There has been significant recent discussion regarding the growing role of upfront combination therapy, and initial results from the AMBITION trial appear to be promising.

DISCLOSURES: Gibbons, Promislow, Dunne - No conflicts to disclose. Davies, Chandy, Stewart, Contreras-Dominguez, Puliese, Mielniczuk have all received consulting and/or speaking fees from Actelion and Bayer, Mielniczuk has had research funding from Actelion and Bayer.

\section{REFERENCES}

1. Simonneau G, Gatzoulis M, Adatia I, et al. Updated clinical classification of pulmonary hypertension. J Am Coll Cardiol 2013;62:D34-41.

2. George PM, Badiger R, Alazawi W, Foster GR, Mitchell JA. Pharmacology and therapeutic potential of interferons. Pharm Ther 2012;135:44-53.

3. Dhillon S, Kaker A, Dosanjh A, Japra D, Van Thiel DH. Irreversible pulmonary hypertension associated with the use of interferon alpha for chronic hepatitis C. Dig Dis Sci 2010;55:1785-90.

4. Ledinek AH, Jazbec SS, Drinovec I, Rot U. Pulmonary arterial hypertension associated with interferon beta treatment for multiple sclerosis: A case report. Mult Scler 2009;15:885-6.

5. Caravita S, Secchi MB, Wu SC, Pierini S, Paggi A. Sildenafil therapy for interferon-b-1a-induced pulmonary arterial hypertension: A case report. Cardiology 2011;120:187-9.

6. Hanoka M, Kubo K, Hayano T, et al. Interferon alpha elevates pulmonary blood pressure in sheep - the role of thromboxane cascase. Eur J Pharmacol 1999;370:145-51.

7. Woods M, Mitchell JA, Wood EG, Barker S, Walcot NR, Rees GM. Endothelin-1 is induced by cytokines in huam vascular smooth muscle cells; evidence for intracellular endothelin converting enzyme. Mol Pharma 1999;64:923-31.

8. Wort SJ, Woods M, Warner TD, Evans TW, Mitchell JA. Endogenously released endothelin-1 from human pulmonary artery smooth muscle promotes cellular proliferation: Relevance to pathogenesis of pulmonary hypertension and vascular remodeling. Am J Resp Cell Mol Biol 2001;25:104-10.

9. Galie N, Corris PA, Frost A, et al. Updated treatment algorithm of pulmonary arterial hypertension. J Am Coll Cardiol 2013;62:D60-72.

10. Kemp K, Savale L, O'Callaghan DS, et al. Usefulness of first-line combination therapy with epoprostenol and bosentan in pulmonary arterial hypertension: An observational study. J Heart Lung Transplant 2012;31:150-8.

11. Galie N, et al. AMBITION: A randomised, multicenter study of first-line ambrisentan and tadalafil combination therapy in subjects with pulmonary arterial hypertension (PAH). Eur Respir J 2014;44(Suppl)58:Abstract 2916. 


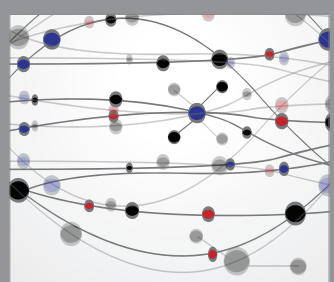

The Scientific World Journal
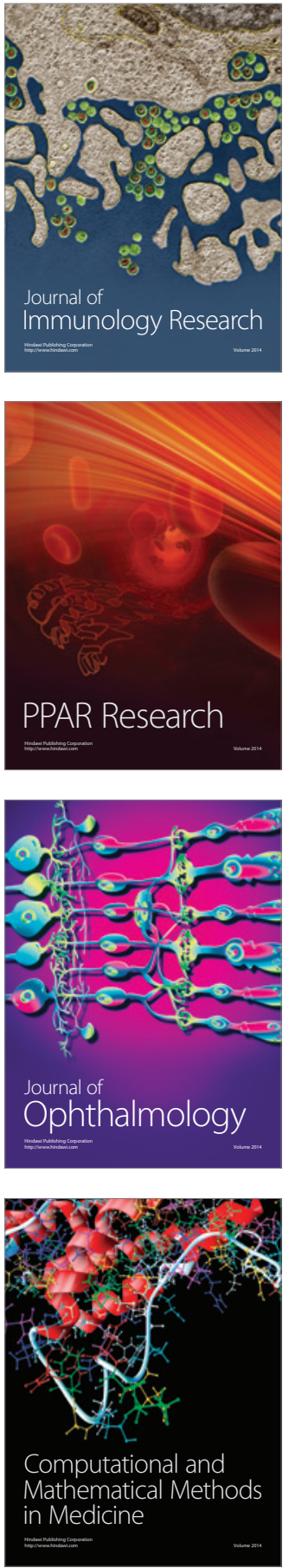

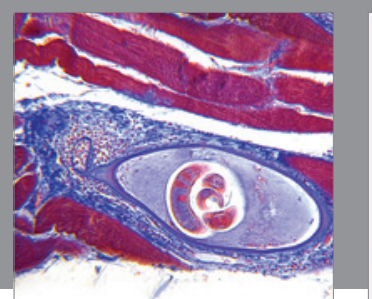

Gastroenterology Research and Practice

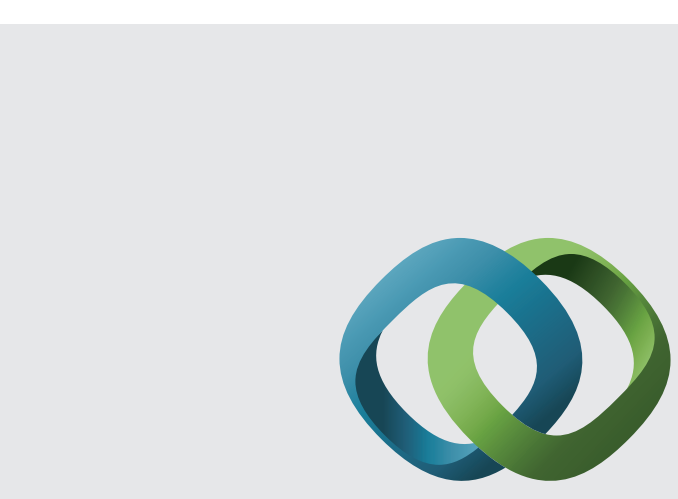

\section{Hindawi}

Submit your manuscripts at

http://www.hindawi.com
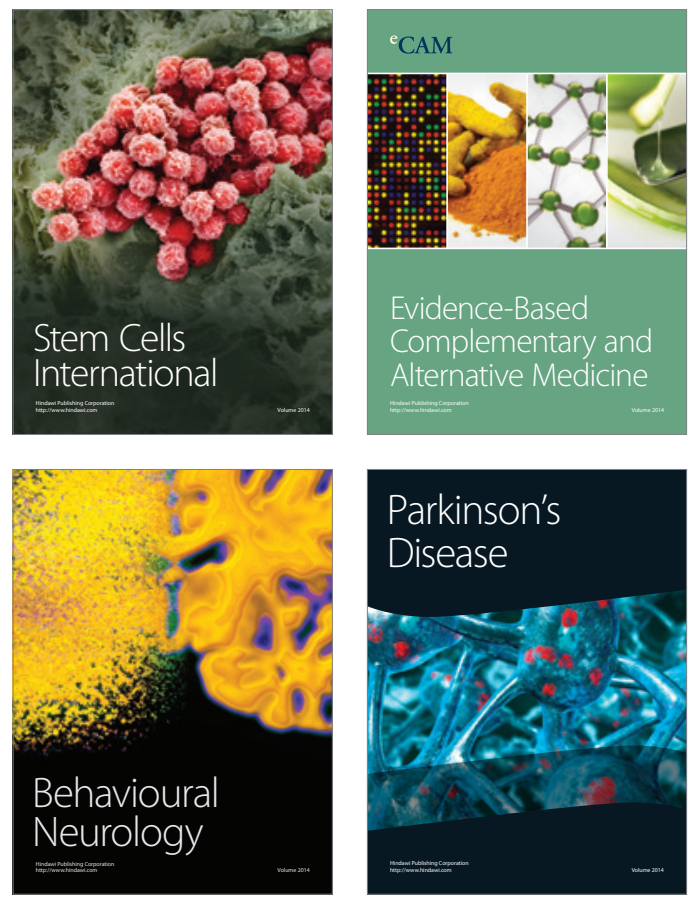
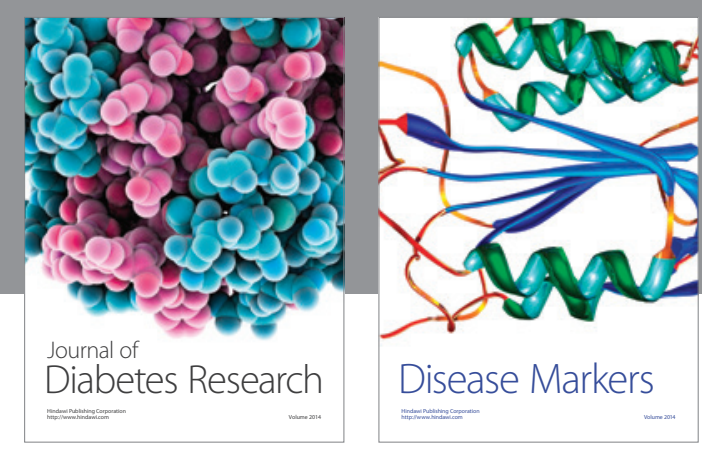

Disease Markers
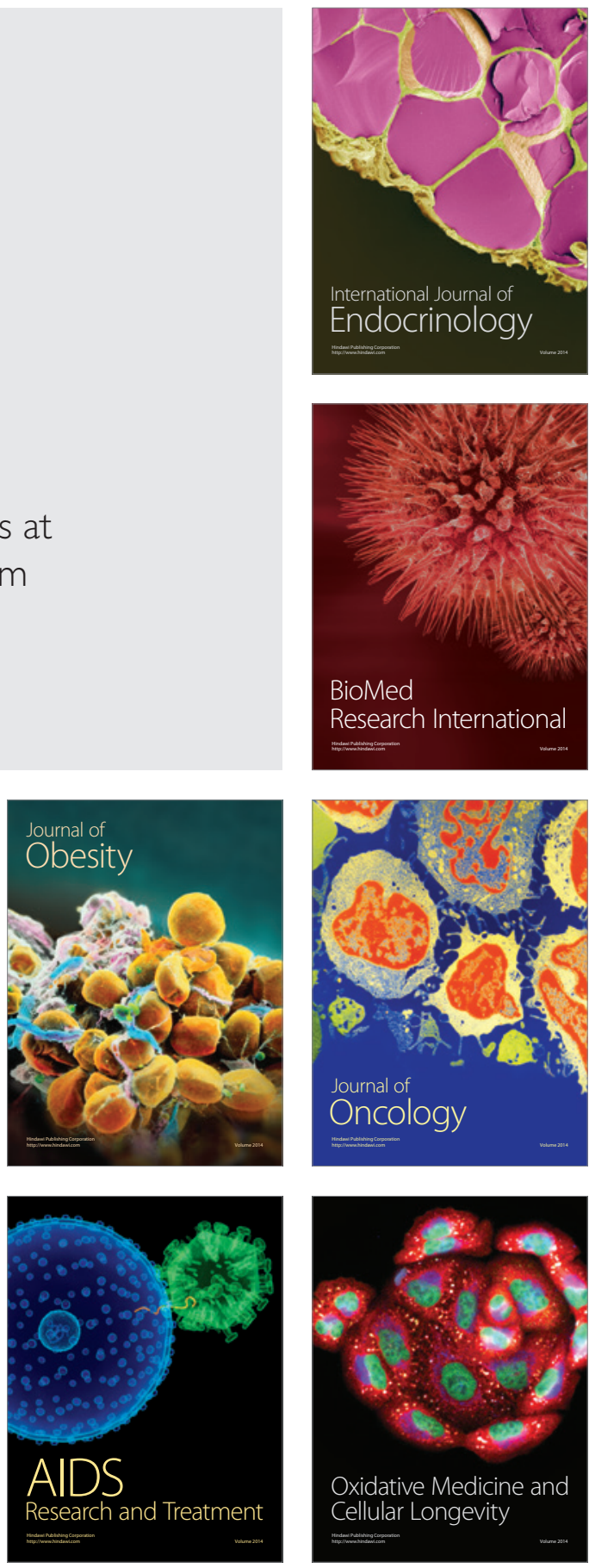